\title{
Remediasi Tanah Tercemar Logam Timbal (Pb) Menggunakan Tanaman Bayam Cabut (Amaranthus tricolor L.)
}

\author{
Novandi $\mathbf{R}^{1}$; Rita Hayati ${ }^{2}$, Titin Anita Zahara ${ }^{3}$ \\ ${ }^{1}$ Program Studi Teknik Lingkungan, Universitas Tanjungpura, Pontianak \\ ${ }^{2}$ Program Studi IImu Tanah, Universitas Tanjungpura, Pontianak \\ ${ }^{3}$ Program Studi Kimia, Universitas Tanjungpura, Pontianak \\ E-mail:novan_robin@yahoo.co.id
}

\begin{abstract}
ABSTRAK
Pencemaran tanah oleh logam timbal $(\mathrm{Pb})$ merupakan salah satu bentuk pencemaran yang sangat berbahaya bagi mahluk hidup. Jumlah logam timbal $(\mathrm{Pb})$ di dalam tanah yang telah melebihi standar baku mutu menyebabkan lingkungan tidak dapat mengadakan pembersihan sendiri (self purification), sehingga diperlukan suatu alternatif pengolahan khusus. Salah satunya adalah dengan metode fitoremediasi menggunakan tanaman bayam cabut (Amaranthus tricolor L.). Tujuan penelitian ini adalah untuk menguji potensi tanaman bayam cabut dalam meremediasi logam $\mathrm{Pb}$ dalam tanah serta proses yang terjadi dalam penyerapan tersebut dan seberapa besar kinetika reaksinya. Penelitian ini dilakukan dengan menanam tanaman bayam cabut yang telah disemai selama 2 minggu di tanah dengan rentang $\mathrm{pH}$ 6,2-6,9 dan telah tercemar $\mathrm{Pb}$ dengan konsentrasi $100 \mathrm{mg} / \mathrm{kg}$. Selanjutnya diukur kadar $\mathrm{Pb}$ di dalam tajuk tanaman yang ditanam di tanah tercemar pada hari ke7, ke-14 dan ke-21 serta tajuk tanaman yang ditanam di tanah tidak tercemar pada hari ke-21. Selain di tajuk, dilakukan juga pengukuran pada akar tanaman yang ditanam di tanah tercemar pada hari ke-21. Berdasarkan hasil penelitian diperoleh nilai bioconcentration factor (BCF) sebesar 0,071 dan translocation factor (TF) sebesar 0,12 . Nilai tersebut menujukan bahwa tanaman bayam cabut termasuk dalam akumulator rendah dan proses yang terjadi dalam remediasi adalah fitostabilisasi. Nilai konstanta laju reaksi $(k)$ proses remediasi ini adalah sebesar 0,1613 hari $^{-1}$ dan mengikuti orde 1 yang menunjukan bahwa laju dari reaksi ini bergantung pada konsetrasi reaktan dipangkatkan dengan satu atau laju reaksi berbanding lurus dengan konsentrasi pereaksi. Walaupun penyerapan $\mathrm{Pb}$ oleh tanaman bayam cabut tergolong rendah, tetapi kondisi tanaman yang secara visual masih sehat dan baik serta pertumbuhannya yang cepat menjadikan tanaman ini masih dapat dipertimbangkan sebagai agen fitoremediasi pencemaran $\mathrm{Pb}$ di tanah.
\end{abstract}

Kata Kunci : Fitoremediasi, logam timbal (Pb), tanaman bayam cabut (Amaranthus tricolor $\mathrm{L}$.)

\section{ABSTRACT}

Lead $(P b)$ is one of the heavy metals which is dangerous for living things because it contaminated soils. High contain of lead in soil, will make soil can not do self purification, so we need a treatment method as alternatives. One of the method is phytoremediation that using plants Amaranthus tricolor L. . The purpose of this research was to examined the potential Amaranthus tricolor L. to remediate lead in soils, the processes in the absorption and to obtain value of reaction kinetics. This research was conducted experimentally with plant Amaranthus tricolor L. that have been sown for 2 weeks in soil with range pH 6.2 to 6.9 and has been contaminated $P b$ with concentration of $100 \mathrm{mg} / \mathrm{kg}$. Then, lead concentrations was measured in the crown (stem and leaves) plants grown in contaminated soil on day 7th, 14th and 21st, and crown (stem and leaves) grown in uncontaminated soil on day 21st. Beside that, in the crown (stem and leaves) plants, also measure the roots of plants grown in contaminated soil on day 21st. Based on the results, the value of bioconcentration factor (BCF) is 0.071 and translocation factor (TF) is 0.12 . It shows that pull spinach plants are included in the low accumulator and processes that occur in the remediation is fitostabilisasi. Value of reaction rate constant ( $k$ ) of this remediation process is at 0.1613 day $^{-1}$ and follow the orde of 1 which shows that rate of this reaction depends on concentration of the reactants raised to one or the reaction rate is directly proportional to the concentration of reactants. Although absorption of lead by pull spinach plants is low, but the condition of plants are still healthy and good visual, and rapid growth make this plant can still be considered as agents of phytoremediation in lead pollution of soil.

Key Words : phytoremediation, lead (Pb), Amaranthus tricolor L. 


\section{Pendahuluan}

Meningkatnya aktivitas manusia baik industri maupun rumah tangga menyebabkan semakin besarnya volume limbah yang dihasilkan dari waktu ke waktu. Sebagian besar limbah tersebut dibuang langsung ke lingkungan tanpa melalui proses pengolahan. Konsenkuensinya adalah terjadinya pencemaran yang banyak menimbulkan kerugian bagi manusia dan lingkungan. Salah satu pencemaran yang dapat terjadi adalah pencemaran tanah, dimana keadaan bahan kimia masuk dan merubah keadaan lingkungan tanah alami. Tanah adalah salah satu faktor pendukung penting dalam kehidupan mahluk hidup di bumi ini. Sebagai dasar keberadaan makhluk hidup termasuk manusia, tanah memiliki peran yang penting untuk siklus materi ataupun ekologi. Oleh sebab itu, menjaga kelestarian tanah agar selalu dapat menjalankan fungsinya dengan baik adalah kewajiban penting bagi setiap mahluk hidup. Akan tetapi, sebagaimana halnya pencemaran air dan udara, pencemaran tanah yang disebabkan oleh faktor alam maupun aktivitas manusia sangat sulit dihindari.

Salah satu bahan pencemar yang menjadi indikator untuk mendeteksi terjadinya pencemaran tanah adalah cemaran logam berat di dalamnya. Faktor yang menyebabkan logam berat termasuk dalam kelompok zat pencemar adalah karena adanya sifat-sifat logam berat yang tidak dapat terurai (non degradable) dan mudah diabsorbsi. Salah satu logam berat yang dapat berpotensi menjadi racun jika berada dalam tanah dengan konsentrasi berlebih adalah $\mathrm{Pb}$ (Timbal). Unsur $\mathrm{Pb}$ merupakan kelompok logam berat yang tidak esensial bagi tumbuhan, bahkan dapat mengganggu siklus hara dalam tanah. Unsur $\mathrm{Pb}$ sampai saat ini masih dipandang sebagai bahan pencemar yang dapat menimbulkan pencemaran tanah dan lingkungan (Juhaeti dkk, 2004).

Logam timbal $(\mathrm{Pb})$ yang mencemari tanah dapat berasal dari kegiatan industri pembuatan lempengan baterai, aki, bahan peledak, pateri, pembungkus kabel, pigmen, cat anti karat, pelapisan logam, serta penggunaan pupuk fosfat dalam bidang pertanian. Selain itu penggunaan bahan bakar yang mengandung timbal menyebabkan udara tercemar oleh timbal, sehingga secara tidak langsung dapat mencemari tanah, baik melalui proses sedimentasi maupun presipitasi. Adanya polutan berupa logam $\mathrm{Pb}$ dalam jumlah yang berlebihan dapat menyebabkan lingkungan tidak dapat mengadakan pembersihan sendiri (self purification). Oleh sebab itu diperlukan suatu metode untuk mengatasi pencemaran $\mathrm{Pb}$ ini. Fitoremediasi merupakan salah satu metode yang dapat menjadi pilihan. Fitoremediasi adalah penggunaan tumbuhan untuk menghilangkan polutan dari tanah atau perairan yang terkontaminasi. Akhir-akhir ini teknik reklamasi dengan fitoremediasi mengalami perkembangan pesat karena terbukti lebih murah dibandingkan metode lainnya (Juhaeti dkk, 2004).

Beberapa tanamanan telah teruji pontensinya dalam meremediasi logam berat di tanah, diantaranya adalah dari genus Amaranthus. Tanaman ini juga dipilih karena mudah tumbuh, didapatkan dan diperbanyak. Tujuan penelitian ini adalah untuk menguji potensi tanaman bayam cabut dalam meremediasi logam $\mathrm{Pb}$ dalam tanah serta proses yang terjadi dalam penyerapan tersebut dan seberapa besar kinetika reaksinya.

\section{Metodologi Penelitian}

\section{a. Tempat dan Waktu Penelitian}

Penelitian dilakukan selama 3 bulan di Laboratorium Teknik Lingkungan Fakultas Teknik Universitas Tanjungpura. Analisis Kapasitas Tukar Kation (KTK) dan logam berat timbal (Pb) dalam tanah serta kadar timbal $(\mathrm{Pb})$ tanaman dilakukan di Balai Riset dan Standarisasi Industri (BARISTAN) Pontianak. Untuk pH tanah diukur di laboratorium Teknik Lingkungan Universitas Tanjungpura.

\section{b. Bahan dan Alat Penelitian}

Bahan yang digunakan dalam penelitian ini adalah akuades, lempengan logam $\mathrm{Pb}$, bibit tanaman bayam cabut (Amaranthus tricolor L.), tanah sebagai media tanam, pupuk organik dan kapur dolomit. Alat yang digunakan dalam penelitian ini adalah reaktor berupa polybag, peralatan pembuat limbah buatan seperti tabung reaksi, labu ukur, gelas ukur, pipet ukur, pipet tetes, batang pengaduk dan timbangan analitik. Selain itu, peralatan analisis parameter seperti oven, tanur (furnace), timbangan analitik, labu kjeldahl, corong gelas, kertas saring, tabung reaksi, cawan petri, plate count, autoclave, inkubator, $\mathrm{pH}$ meter dan AAS. 


\section{c. Metode Penelitian}

1. Pembenihan

Tahap pembenihan ini merupakan tahap awal sebagai media pembibitan dan pertumbuhan awal agar diperoleh tanaman yang memiliki umur dan kondisi yang sama. Bibit tanaman bayam yang digunakan adalah bibit tanaman bayam hijau yang telah siap ditanam. Biji disemai pada tanah yang telah ditempatkan pada media tanam berupa bekas gelas-gelas air mineral Tanaman disiram setiap sore hari. Pembibitan dilakukan selama 14 hari sampai bibit tumbuh dan memiliki akar cukup kuat untuk dipindahkan ke polybag yang telah berisi media tanam.

\section{Penyiapan Media Tanam}

Tanah gambut diambil dari sekitar komplek Universitas Tanjungpura kemudian tanah dibersihkan dari sisa-sisa akar dan jaringan tanaman yang berukuran besar lalu digerai selama 2 hari. Tanah kemudian ditimbang sebanyak $5 \mathrm{~kg}$, diberi kapur dan dimasukkan ke polybag, kemudian diinkubasi selama 2 minggu. Tanah dikapur untuk menaikkan $\mathrm{pH}$ tanah gambut. Dosis kapur yang digunakan $100 \mathrm{gr} / 5 \mathrm{~kg}$ tanah (1 polybag). Setelah 1 minggu, tanah kemudian diberi pupuk organik sebanyak 500 gr pada masing-masing polybag untuk menambah kesuburan tanah. Tanah kemudian diukur

Tanah yang telah diberi kapur dan pupuk kandang kemudian dicemari oleh pencemar buatan $\mathrm{Pb}$ dengan konsentrasi 100 ppm. Konsentrasi ini sesuai dengan percobaaan yang telah dilakukan oleh Syarifuddin Liong dkk dari Universitas Hasanuddin Makassar. Pada penelitian tersebut diketahui bahwa pada konsentrasi 100 ppm terjadi serapan puncak logam $\mathrm{Pb}$ pada tanaman kangkung darat. Pemberian dilakukan dengan mencampurkan larutan $\mathrm{Pb}$ dengan konstrasi $500 \mathrm{ppm}$ ke dalam $5 \mathrm{~kg}$ tanah. Cara pembuatan pencemar logam $\mathrm{Pb}$ buatan yang digunakan adalah sebagai berikut:

- Pembuatan larutan induk 5000 ppm

Dilarutkan 5 gram logam $\mathrm{Pb}$ dalam $30 \mathrm{ml}$ asam nitrat $2 \mathrm{M}$ pada gelas ukur $100 \mathrm{ml}$, lalu diencerkan dengan aquades. Selanjutnya dimasukkan dalam labu ukur $1000 \mathrm{ml}$ dan ditepatkan volumenya dengan aquades. Larutan induk ini setara dengan 5000 mg/l atau 5000 ppm kadar Pb.

- Pembuatan Larutan Pb 500 ppm.

Larutan induk 5000 ppm dipipet 100 ml kemudian dimasukan ke dalam labu ukur 1000 ml lalu ditambahkan dengan aquades sampai batas ukur.

Larutan $\mathrm{Pb} 500$ ppm yang telah dibuat kemudian secara merata disiram ke masing-masing polybag selama 24 jam agar limbah homogen di dalam tanah. Untuk mencapai kondisi yang optimal selama penelitian, kondisi polybag yang digunakan sebagai reaktor proses dilengkapi dengan plastik agar tidak terjadi kebocoran saat dilakukan penyiraman terhadap tumbuhan.

\section{Penanaman, Aklimatisasi dan Analisa Parameter}

Bibit tanaman bayam cabut (Amaranthus tricolor L.) yang telah tumbuh dan berumur 14 hari kemudian ditanam di dalam beberapa polybag yang sebelumya telah diisi media tanam. Satu polybag masing-masing hanya diisi oleh lima tanaman. Pada penelitian ini terdapat 10 tanaman yang ditanam pada tanah yang tidak dicemari logam $\mathrm{Pb}$ dan 105 tanaman (21 polybag) yang ditanam pada tanah berisi tanah dicemari $\mathrm{Pb}$. bayam. Setiap sore, tanaman disiram dengan akuades untuk menjaga kondisi tanaman tetap segar.

Pada 7 hari pertama dilakukan juga tahap aklimatisasi. Tahap aklimatisasi merupakan upaya penyesuaian fisiologis atau adaptasi dari tanaman terhadap lingkungan tempat penelitian. Dari tahap aklimatiasi ini diharapkan tanaman yang dipindahkan dari tempat pembenihan dapat tumbuh pada polybag yang menjadi media penelitian.

Tanaman bayam yang telah ditanam di dalam media tanah dicemari $\mathrm{Pb}$ kemudian dicabut pada hari yang ke-7, hari ke-14, dan hari ke-21 dihitung dari sejak tanaman dipindahkan ke polybag. Pada hari ke-7 pencabutan dilakukan dengan mencabut sebanyak 15 tanaman (3 polybag) untuk satu sampel pengukuran. Pada hari ke-7 ukuran tanaman masih cukup kecil, sehingga diperlukan cukup bayak tanaman agar dapat diuji kadar timbalnya. Pada hari ke-14 dan ke-21 pencabutan dilakukan dengan mencabut sebanyak 10 tanaman (2 polybag) untuk satu sampel pengukuran. Pada masingmasing waktu pencabutan terdapat 3 sampel, sehingga pada hari ke-7 dilakukan pencabutan 
sebanyak 45 tanaman (9 polybag) dan pada hari ke-14 dan ke-21 sebanyak 30 tanaman (6 polybag). Pengukuran kadar $\mathrm{Pb}$ pada tanaman yang ditanam pada media tanah yang tidak dicemari logam $\mathrm{Pb}$ dilakukan bersamaan pada pencabutan di hari ke-21.

Sampel tanaman yang telah dicabut dicuci dengan akuades terlebih dahulu sebelum dianalisis untuk menghilangkan debu-debu dan kotoran lainnya yang dapat memberikan kesalahan pada hasil analisis. Sampel tanaman tersebut kemudian dipisahkan antara bagian tajuk dan akarnya. Setelah itu sampel tanaman dikeringakan dengan oven pada suhu $70{ }^{\circ} \mathrm{C}$. Sampel yang telah kering kemudian digerus dan dimasukan kedalam plastik agar tidak terkontaminasi serta diberi nomor urut sesuai dengan nomor percobaan atau perlakuan. Sampel tanaman yang telah siap diuji kemudian didestruksi dengan destruksi basah dan diukur dengan AAS.

\section{d. Variabel atau Data}

Variabel atau data yang dikumpulkan pada penelitian ini terdiri dari :

1. Variabel atau data yang dikumpulkan dari tanah yang digunakan sebagai media tanam dalam penelitian ini, adalah Kadar Pb, pH dan Kapasitas Tukar Kation (KTK) tanah.

2. Variabel atau data yang dikumpulkan untuk setiap tanaman bayam cabut (Amaranthus tricolor L.) yang dicabut dari polybag adalah kadar $\mathrm{Pb}$ dalam tajuk tanaman pada hari yang ke-7, hari ke14, dan hari ke-21 dihitung dari sejak tanaman dipindahkan ke polybag. Pada setiap waktu pengukuran terdapat 3 variabel pengukuran. Hasil pengukuran pada ketiga variabel tersebut kemudian dirata-ratakan, sehingga variabel atau data yang diperoleh dari proses pengukuran, yaitu :

- Rata-rata kadar Pb dalam tajuk pada hari ke-7

- Rata-rata kadar Pb dalam tajuk pada hari ke-14

- Rata-rata kadar Pb dalam tajuk pada hari ke-21

Untuk kadar Pb dalam akar diukur dari sampel akar tanaman pada hari ke-21.

3. Variabel atau data yang dikumpulkan dari polybag berisi tanah tidak dicemari logam $\mathrm{Pb}$ yang ditanam tanaman bayam cabut (Amaranthus tricolor L.) adalah kadar timbal dalam tajuk tanaman pada hari ke-21.

\section{e. Analisis Akhir}

Data-data yang diperoleh dari penelitian yang dilakukan akan dianalisa melalui hal-hal berikut :

1. Potensi tanaman bayam cabut (Amaranthus tricolor L.) dalam meremediasi tanah tercemar logam timbal $(\mathrm{Pb})$ dianalisa dengan menghitung nilai BCF. Nilai BCF menunjukkan perbandingan antara konsentrasi logam berat pada tanaman dengan logam berat dalam tanah (Wei et al. dalam hayati 2010). Nilai BCF yang diharapkan > 1. Nilai BCF 1-10 menunjukkan tumbuhan tergolong akumulator tinggi, 0,1-1 menunjukan tergolong akumulator sedang, 0,01-0,1 menunjukkan tergolong akumulator rendah, dan $<0,01$ tanaman tergolong nonakumulator (Malayeri et al., 2008).

2. Proses yang terjadi pada tanaman bayam cabut (Amaranthus tricolor L.) dalam mengurangi logam timbal $(\mathrm{Pb})$ dianalisa dengan menghitung nilai TF. Nilai TF menunjukkan perbandingan antara konsentrasi logam di tajuk dengan konsentrasi logam di akar (Wei et al. dalam hayati 2010). Nilai TF yang diharapkan $>1$. Pada tanaman hiperakumulator atau akumulator, nilai TF $>1$ digunakan untuk tujuan fitoekstraksi, sebaliknya $T F<1$ sebagai ekskluder (digunakan untuk tujuan fitostabilisasi) (Haque et al., 2008).

3. Besar kinetika reaksi remediasi logam timbal $(\mathrm{Pb})$ pada tanaman bayam cabut (Amaranthus tricolor $\mathrm{L}$.) dianalisa dengan mengamati kadar $\mathrm{Pb}$ dalam tanaman dan menghitung nilai kinetika reaksi penyerapannya dengan menetapkan kinetika reaksi orde 1 atau 2. Orde reaksi ditentukan dengan melihat kelinieritasan kurva yang ditunjukan oleh koefisien korelasi linier.

\section{Hasil Dan Pembahasan}

\section{a. Analisa Pendahuluan}

Analisis pendahuluan dilakukan untuk mengetahui karakeristik tanah yang digunakan pada penelitian ini. Karakteristik tanah yang dianalisa pada penelitian ini adalah $\mathrm{pH}$ dan Kapasitas Tukar 
Kation (KTK) dan kadar logam $\mathrm{Pb}$. Tanah yang akan dianalisa terdiri dari tanah awal atau tanah gambut yang belum mendapatkan perlakukan, tanah setelah mengalami proses pemupukan dan pengapuran serta tanah setelah diberikan limbah buatan $\mathrm{Pb}$ dengan konsentrasi $100 \mathrm{mg} / \mathrm{kg}$. Hasil analisa tanah-tanah tersebut dapat dilihat pada Tabel 1 di bawah ini :

Tabel 1. Hasil Analisa Tanah

\begin{tabular}{lccc}
\multicolumn{1}{c}{ Tanah } & $\mathrm{pH}$ & $\begin{array}{c}\text { KTK } \\
\text { (Meq/100g) }\end{array}$ & Kadar Pb (mg/kg) \\
\hline $\begin{array}{l}\text { Tanah awal } \\
\text { Tanah setelah pengapuran dan }\end{array}$ & 3,4 & 62,6 & 0,463 \\
$\begin{array}{l}\text { pemupukan } \\
\text { Tanah sesudah dicemari limbah }\end{array}$ & 7,3 & 31,2 & 3,56 \\
$\mathrm{~Pb}$ & 6,3 & 26,0 & 127 \\
\hline
\end{tabular}

Berdasarkan hasil analisis yang diperoleh tanah gambut yang digunakan pada penelitian ini memiliki pH yang sangat asam, yaitu 3,4. Berdasarkan kriteria unsur hara tanah dari Laboratorium Sentral Fakultas Pertanian Universitas Sumatera Utara (USU), nilai pH tersebut termasuk tanah sangat asam $(<4,5)$. Tingkat kemasaman tanah gambut yang tinggi dipengaruhi oleh keberadaan asam-asam organik di dalamnya. Ion $\mathrm{H}^{+}$dalam tanah gambut berada dalam bentuk gugus fungsional asam-asam organik terutama dalam bentuk gugus karboksilat $(-\mathrm{COOH})$ dan gugus hidroksil dari fenolat $(-\mathrm{OH})$. Gugus tersebut merupakan asam lemah yang dapat terdissosiasi menghasilkan ion $\mathrm{H}^{+}$, dan mampu mempertahankan reaksi tanah terhadap perubahan kemasaman tanah (Riwandi, 2001). Tanah yang memiliki $\mathrm{pH}$ terlalu asam seperti tanah yang digunakan pada penelitian ini dapat menyebabkan kemampuan akar tanaman dalam menyerap unsur-unsur hara dalam tanah menjadi berkurang. Pada umumnya unsur hara makro mudah diserap akar tanaman pada $\mathrm{pH}$ tanah sekitar netral, karena pada $\mathrm{pH}$ tersebut kebanyakan unsur hara mudah larut dalam air. Pengapuran merupakan salah satu metode yang dapat digunakan untuk meningkatkan nilai pH. Pada penelitian ini dilakukan pemberian kapur dolomit kedalam tanah yang kemudian tanah diinkubasi selama 2 minggu. Setelah masa inkubasi terjadi peningkatan $\mathrm{pH}$ yang cukup signifikan, yaitu sebesar 7,3 . Nilai $\mathrm{pH}$ tersebut termasuk dalam nilai yang tinggi dan bersifat netral. Hal ini terjadi karena unsur Ca dan $\mathrm{Mg}$ yang terdapat dalam dolomit melalui reaksi hidrolisis dapat melepaskan ion $\mathrm{OH}^{-}$yang berpengaruh terhadap peningkatan $\mathrm{pH}$ tanah. Selain itu pemberian pupuk organik sebagai penambah unsur-unsur hara yang diperlukan oleh tanaman secara tidak langsung juga dapat meningkatkan nilai $\mathrm{pH}$ tanah. Nilai pH pupuk organik yang bersifat netral menyebabkan naiknya tingkat kebasaan tanah.

Berdasarkan hasil analisa yang diperoleh tanah gambut yang digunakan pada penelitian ini memiliki KTK sebesar 62,6 meq/100 g. Berdasarkan kriteria unsur hara tanah dari Laboratorium Sentral Fakultas Pertanian Universitas Sumatera Utara (USU), nilai tersebut termasuk KTK sangat tinggi (> $40 \mathrm{meq} / 100 \mathrm{~g}$ ). KTK yang tinggi ini dapat disebabkan oleh banyaknya kandungan asam-asam organik pada tanah gambut. Asam-asam organik dengan gugus karboksil (- $\mathrm{COOH})$ dan gugus fenol ($\mathrm{OH})$ memberikan kontribusi yang besar bagi tingginya nilai KTK tanah gambut. Pemberian kapur dan pupuk menyebabkan nilai KTK tanah turun menjadi $31,2 \mathrm{meq} / 100 \mathrm{~g}$. Meskipun mengalami penurunan, nilai KTK tanah masih termasuk KTK tinggi (26-40 meq/100 g)berdasarkan kriteria unsur hara tanah. Nilai KTK tanah setelah diberi pencemar buatan $\mathrm{Pb}$ juga mengalami penurunan menjadi $26,00 \mathrm{meq} / 100 \mathrm{~g}$, tetapi masih masuk dalam kriteria tanah dengan KTK tinggi.

Berdasarkan hasil analisa kadar $\mathrm{Pb}$ yang terdapat pada tanah awal dari penelitian ini adalah sebesar $0,463 \mathrm{mg} / \mathrm{kg}$. Kadar $\mathrm{Pb}$ ini masih di bawah batas kritis logam berat $\mathrm{Pb}$ di dalam tanah. Setelah diberi kapur dolomit dan pupuk organik terjadi peningkatan kadar $\mathrm{Pb}$ menjadi $3,56 \mathrm{mg} / \mathrm{kg}$. Peningkatan kadar $\mathrm{Pb}$ ini dapat disebabkan oleh kadar $\mathrm{Pb}$ dalam pupuk organik dan kapur dolomit. Berdasarkan Alloway dalam Rumanjar 2010, kandungan $\mathrm{Pb}$ di dalam pupuk organik dapat mencapai $1,1-27 \mathrm{mg} / \mathrm{kg}$ dan di dalam kapur dapat mencapai 20- $1250 \mathrm{mg} / \mathrm{kg}$. Namun tanah dengan $\mathrm{kadar} \mathrm{Pb}$ sebesar 3,56 mg/kg tersebut masih termasuk dalam kriteria tanah tidak tercemar $\mathrm{Pb}$. Pencemar buatan $\mathrm{Pb}$ yang diberikan pada penelitian ini adalah $\mathrm{Pb}$ dengan konsentrasi $100 \mathrm{mg} / \mathrm{kg}$. Pencemar diberikan dengan mencampurkan tanah sebanyak $5 \mathrm{~kg}$ dan larutan $\mathrm{Pb}$ dengan konsentrasi 500 
$\mathrm{mg} / \mathrm{kg}$. Tanah yang telah dicampur dan dihomogenkan kemudian diukur kadar $\mathrm{Pb}$ di dalamnya. Berdasarkan hasil penelitian diperoleh hasil pengukuran sebesar $127 \mathrm{mg} / \mathrm{kg}$. Kadar timbal yang terdapat di dalam tanah yang dicemari ini telah melebihi batas kritis logam berat $\mathrm{Pb}$ dalam tanah yang ditetapkan oleh Ministry of State for Population and Enviromental of Indonesia, and Dalhousie, University Canada (1992), yaitu $100 \mathrm{mg} / \mathrm{kg}$.

\section{b. Hasil Pengukuran Kadar Timbal (Pb) dalam Tanaman}

Pada penelitian ini tanaman bayam cabut (Amaranthus tricolor L.) ditanam pada media tanah yang dikontaminasi logam timbal $(\mathrm{Pb})$ dengan konsentrasi $100 \mathrm{mg} / \mathrm{kg}$. Selama penelitian dilakukan pengukuran terhadap kadar timbal dalam tajuk tanaman untuk mengetahui kemampuan tanaman bayam cabut (Amaranthus tricolor L.) dalam menyerap logam $\mathrm{Pb}$ yang ada di dalam tanah. Pencabutan dan pengukuran kadar $\mathrm{Pb}$ dalam tanaman dilakukan sebanyak 3 kali selama 3 minggu, yaitu pada hari ke-7, ke-14 dan ke-21 sejak tanaman dipindahkan ke reaktor berupa polybag. Pada setiap waktu pengukuran dilakukan pengukuran pada 3 sampel tajuk tanaman. Pada hari ke-7 masing-masing sampel terdiri dari 15 tajuk tanaman, sedangkan pada hari ke-14 dan ke-21 terdiri dari 10 tajuk tanaman. Hasil pengukuran kadar timbal dalam tajuk tanaman bayam cabut (Amaranthus tricolor L.) ditampilkan dalam Tabel 2 :

Tabel 2. Hasil Pengukuran Kadar Timbal dalam Tajuk Tanaman Bayam Cabut

\begin{tabular}{lccc}
\hline Tanaman & $\begin{array}{c}\text { pH } \\
\text { Tanah }\end{array}$ & Kadar Pb dalam Tajuk & $\begin{array}{c}\text { Rata-rata Kadar Pb } \\
\text { dalam Tajuk Perwaktu } \\
\text { Pencabutan }\end{array}$ \\
\hline Hari ke-7 B & 6,2 & $<0,100$ & $<0,100$ \\
Hari ke-7 C & 6,4 & $<0,100$ & \\
\hline Hari ke-14 A & 6,4 & 0,533 & 0,435 \\
Hari ke-14 B & 6,9 & 0,672 & \\
Hari ke-14 C & 6,2 & $<0,100$ & 0,957 \\
\hline Hari ke-21 A & 6,8 & 0,945 & \\
Hari ke-21 C & 6,5 & 0,968 & \\
\hline
\end{tabular}

Berdasarkan Tabel 2 dapat dilihat bahwa kadar logam timbal $(\mathrm{Pb})$ pada tanaman semakin meningkat seiring dengan meningkatnya waktu penanaman. Pada akhir pengamatan tingkat akumulasi logam timbal lebih besar daripada di awal pengamatan. Hasil pengukuran tersebut menunjukan pada waktu pengukuran 7 hari telah terjadi penyerapan logam timbal $(\mathrm{Pb})$, tetapi masih dalam kadar yang sangat kecil. Pada waktu pengukuran selanjutnya terjadi peningkatan penyerapan, yang terjadi pada hari ke-14 dan ke-21 hari. Kadar $\mathrm{Pb}$ yang terserap olah tanaman bayam cabut (Amaranthus tricolor L.) pada hari ke-7 sangat kecil yaitu kurang dari 0,100 mg/kg. Hal ini dapat disebabkan karena ukuran tanaman pada hari ke-7 masih sangat kecil, sehingga kemampuan tajuk tanaman dalam menyerap logam timbal juga masih sangat kecil. Jaringan tanaman yang masih kecil belum bekerja secara maskimal, salah satunya dalam proses penyerapan logam dalam tanah.

Kadar timbal dalam tanaman menunjukan peningkatan pada hari ke-14 dan ke-21, yaitu sebesar $0,435 \mathrm{mg} / \mathrm{kg}$ dan $0,957 \mathrm{mg} / \mathrm{kg}$. Kenaikan konsentrasi disebabkan tanaman bayam masih berada dalam proses pertumbuhan sehingga proses penyerapan dan akumulasi timbal $(\mathrm{Pb})$ masih berlangsung. Pertumbuhan tanaman yang semakin besar menyebabkan sistem kerja dari proses penyerapan juga meningkat. Dari 3 waktu pengukuran yang dilakukan diketahui bahwa penyerapan maksimal terjadi pada hari ke-21. Pada waktu pengukuran tersebut tanaman tidak menujukan penurunan fisik atau kondisi jenuh.

Pada bagian akar tanaman bayam cabut (Amaranthus tricolor L.) kadar timbal yang terakumulasi lebih banyak daripada bagian tajuk, yaitu sebesar $8,10 \mathrm{mg} / \mathrm{kg}$. Kadar timbal tersebut diukur pada akar tanaman yang berumur 21 hari. Berdasarkan hasil pengukuran tersebut dapat diketahui total kadar timbal $(\mathrm{Pb})$ yang terakumulasi pada tanaman bayam cabut (Amaranthus tricolor $\mathrm{L}$.) yang terdiri dari akar dan tajuk dihari maksimal yaitu hari ke-21 sebesar $9,057 \mathrm{mg} / \mathrm{kg}$.

Salah satu mekanisme tanaman dalam mentoleransi toksisitas logam berat adalah melalui fenomena selektifitas serapan ion dari media tumbuhnya (Kabata-Pendias \& Pendias, 2001). 
Penurunan serapan tanaman terhadap logam berat berkenaan dengan 3 hal, yaitu: (1) akibat penurunan kadar fraksi aktif logam berat dalam media tumbuh, atau (2) peningkatan selektifitas tanaman dalam menyerap unsur dari media tumbuh, atau (3) kombinasi keduanya (Alloway, 1995 dalam Hayati, 2010). Dalam penelitian ini sampai hari ke-21 tidak terjadi penurunan serapan logam $\mathrm{Pb}$ oleh tanaman. Hal ini menunjukan bahwa fraksi aktif logam berat dalam media tumbuh belum mengalami penurunan dan tanaman belum mengalami selektifitas yang tinggi dalam menyerap unsur dari media tumbuh.

Hasil pengukuran terhadap tanaman yang ditanam pada media tanah tidak tercemar logam $\mathrm{Pb}$ adalah sebesar 0,436 mg/kg. Meskipun tidak diberikan pencemar buatan, tetapi berdasarkan analisa yang dilakukan diketahui bahwa tanah awal yang digunakan telah mengadung $\mathrm{Pb}$ sebesar 3,56 $\mathrm{mg} / \mathrm{kg}$. Logam $\mathrm{Pb}$ inilah yang kemudian diserap oleh tanaman. Hal ini juga sesuai dengan penelitian yang dilakukan Liong dkk (2010) yang meyatakan bahwa semakin tinggi tingkat konsentrasi logam $\mathrm{Pb}$ di dalam tanah, maka semakin tinggi tingkat penyerapan $\mathrm{Pb}$ pada tanaman kangkung. Selain itu, untuk hasil penurunan kadar timbal dalam tanah akhir atau tanah pada hari ke-21 diperoleh nilai sebesar 7,11 mg/kg. Hasil ini menunjukan bahwa sebagian besar logam $\mathrm{Pb}$ di dalam tanah telah hilang karena terserap oleh tanaman.

Kadar timbal $(\mathrm{Pb})$ di dalam tajuk pada hari ke-21 sebesar 0,957 mg/kg menujukan bahwa tanaman bayam ini telah melebihi batas maksimum cemaran timbal dalam sayuran berdasarkan SNI 7387:2009, yaitu sebesar $0,5 \mathrm{mg} / \mathrm{kg}$. Oleh sebab itu masyarakat perlu memperhatikan tanah yang digunakan sebagai media tanam sebelum menanam tanaman bayam. Media tanam yang telah tercemar timbal dapat menyebabkan tanaman bayam tercemar dan tidak layak konsumsi.

\section{c. Perhitungan dan Analisis Nilai Bioconcentration Factor (BCF)}

Nilai Bioconcentration Factor (BCF) pada penelitian ini dihitung dengan membandingkan kadar logam $\mathrm{Pb}$ di dalam tanaman dengan kadar $\mathrm{Pb}$ di dalam tanah. Kadar logam $\mathrm{Pb}$ pada tanaman yang digunakan merupakan kadar $\mathrm{Pb}$ yang tertinggi atau maksimal, yaitu pada hari ke-21. Total kadar $\mathrm{Pb}$ dalam tanaman merupakan penjumlah dari kadar $\mathrm{Pb}$ dalam tajuk $(0,957 \mathrm{mg} / \mathrm{kg})$ dan kadar $\mathrm{Pb}$ dalam akar tanaman $(8,10 \mathrm{mg} / \mathrm{kg})$, sehingga total kadar Pb dalam tanaman sebesar 9,057 mg/kg. Kadar Pb dalam tanah yang digunakan adalah kadar $\mathrm{Pb}$ yang terukur pada tanah setelah pemberian limbah buatan $\mathrm{Pb}$ dengan kadar $100 \mathrm{mg} / \mathrm{kg}$, yaitu sebesar $127 \mathrm{mg} / \mathrm{kg}$. Berdasarkan nilai yang diketahui, maka diperoleh hasil perhitungan nilai BCF sebesar 0,071. Nilai tersebut berada pada rentang $0,01-0,1$ yang menujukan bahwa tanaman bayam cabut (Amaranthus tricolor L.) termasuk dalam tanaman bersifat akumulator rendah dalam penyerapan logam $\mathrm{Pb}$. Ada beberapa faktor yang mempengaruhi serapan dan akumulasi logam berat dalam jaringan tanaman, antara lain logam yang diserap, karakteristik tanah dan jenis tanaman yang digunakan. Ketiga faktor tersebut saling mempengaruhi satu sama lain. Timbal $(\mathrm{Pb})$ merupakan logam yang cendrung terakumulasi dan tersedimentasi dalam tanah karena kelarutannya yang rendah dan relatif bebas dari degradasi mikroorganisme (Devies dalam Adelia, 2004). Nilai pH tanah yang tinggi dapat merubah logam timbal menjadi senyawa yang mengendap. Penyerapan timbal oleh tanaman melalui akar hanya terjadi apabila timbal yang terdapat di dalam tanah berbentuk senyawa yang larut air. Dalam peneltian ini $\mathrm{pH}$ tanah yang digunakan cukup tinggi, sehingga menyebabkan logam $\mathrm{Pb}$ yang terdapat dalam tanah mengendap dan tidak dapat diserap oleh tanaman. Nilai pH tanah yang medekati netral selama proses penelitian menyebabkan larutan timbal lebih cendrung mengendap dalam tanah daripada terserap oleh akar tanaman.

Tanaman dapat menyerap logam $\mathrm{Pb}$ pada saat kondisi kesuburan, kandungan bahan organik dan KTK yang tanah rendah. Pada keadaan ini logam berat Pb akan terlepas dari ikatan tanah dan berupa ion yang bergerak bebas pada larutan tanah. Jika logam lain tidak mampu menghambat keberadaannya, maka akan terjadi serapan $\mathrm{Pb}$ oleh akar tanaman (Charlena, 2004). Timbal yang berada di tanah juga hampir selalu terikat kuat oleh bahan organik atau koloid terpresipitasi (Zimdhal dan Koeppe dalam Adelia, 2004). KTK dan bahan organik yang tinggi dalam tanah gambut yang digunakan pada penelitian ini juga dapat menyebabkan kurangnya tingkat penyerapan $\mathrm{Pb}$ dalam tanaman.

Nilai BCF bayam cabut (Amaranthus tricolor L.) yang tergolong dalam akumulator rendah memang menunjukan kemampuan tanaman bayam dalam menyerap logam $\mathrm{Pb}$ rendah. Namun 
kondisi tanaman bayam yang secara visual setelah 21 hari ditanam di tanah yang tercemar $\mathrm{Pb}$ tidak menunjukan penurunan kondisi yang signifikan atau belum menunjukan gejala keracunan maka tanaman ini masih memiliki potensi untuk dijadikan pertimbangan sebagai salah satu fitoremediator dalam mengolah tanah tercemar $\mathrm{Pb}$. Tanaman bayam memiliki ketahanan yang baik terhadap radiasi atau sifat toksik dari logam $\mathrm{Pb}$. Selain itu proses pertumbuhan tanaman bayam yang relatif cepat menjadi kelebihan lain dari tanaman bayam sebagai fitoremediator logam $\mathrm{Pb}$ dalam tanah.

Melihat kondisi tanaman yang tidak dapat lagi dikonsumsi, maka setelah polutan terakumulasi dalam tanaman perlu dilakukan pengelolaan khusus terhadap tanaman yang telah digunakan. Mangkoedihardjo dan Samudro (2010) menjelaskan beberapa teknologi potensial yang dapat diterapkan dalam menangani tumbuhan pascaguna pengolahan lingkungan berdasarkan batasan nilai BCF. Teknologi yang dapat diterapkan pada tanaman yang memiliki nilai BCF $<1$ seperti pada tanaman bayam cabut (Amaranthus tricolor L.) ini antara lain teknologi pengomposan, penguraian anaerobik (digestion) atau pembakaran skala kecil. Tanaman dengan nilai BCF $<1$ memiliki paparan zat toksik yang yang cukup kecil sehingga masih dapat dimanfaatkan dalam proses pengomposan dan penguraian anaerobik (digestion). Proses pembakaran skala kecil yang dilengkapi dengan pencegahan pencemaran udara juga cukup layak digunakan untuk tumbuhan dengan nilai BCF kecil, yaitu BCF $<1$.

\section{d. Perhitungan dan Analisis Nilai Translocation Factor (TF)}

Nilai translocation factor (TF) pada penelitian ini dihitung dengan membandingkan kadar logam $\mathrm{Pb}$ di dalam tajuk dengan kadar $\mathrm{Pb}$ di dalam akar. Kadar logam $\mathrm{Pb}$ pada tajuk dan akar yang digunakan merupakan kadar $\mathrm{Pb}$ yang tertinggi atau maksimal, yaitu pada hari ke-21. Kadar pada tajuk tanaman pada hari ke-21 adalah sebesar 0,957 mg/kg dan kadar $\mathrm{Pb}$ dalam akar pada adalah sebesar $8,10 \mathrm{mg} / \mathrm{kg}$. Berdasarkan nilai yang diketahui, maka diperoleh hasi perhitungan nilai TF sebesar 0,12. Nilai tersebut lebih kecil daripada $1(<1)$ sehingga mekasnisme atau proses yang terjadi pada penanaman bayam cabut (Amaranthus tricolor L.) dalam menyerap logam $\mathrm{Pb}$ adalah fitostabilisasi. Menurut Pivetz (2001) yang dipublikasikan oleh EPA (Environmental Protection Agency), fitostabilisasi adalah proses penempelan zat-zat kontaminan tertentu pada akar yang tidak mungkin terserap ke dalam batang tumbuhan. Zat-zat tersebut menempel erat (stabil) pada akar sehingga tidak akan terbawa oleh aliran air atau media.

Proses fitostabilisasi yang terjadi dapat disebabkan bagian akar tanaman langsung berhubungan dengan tanah yang tercemar logam $\mathrm{Pb}$. Logam $\mathrm{Pb}$ dalam tanah yang diserap oleh tanaman bayam, terlebih dahulu diakumulasi dalam akar sebelum didistribusikan ke batang dan daun. Sel-sel akar tumbuhan umumnya mengandung konsentrasi ion yang lebih tinggi daripada medium disekitarnya (Fitter dan Hay, 1991). Beraneka ragam unsur dapat ditemukan didalam tubuh tumbuhan, tetapi tidak berarti bahwa seluruh unsur-unsur tersebut dibutuhkan tumbuhan untuk kelangsungan hidupnya. Unsur hara dapat kontak dengan permukaan akar melalui 3 cara, yakni : 1) secara difusi dalam larutan tanah; 2) secara pasif oleh aliran tanah, dan 3) akar tumbuh kearah posisi hara dalam matrik tanah. Serapan hara oleh akar dapat bersifat akumulatif, selektif, satu arah (unit directional), dan tidak dapat jenuh (Lakitan, 2001).

Pergerakan logam dari akar ke tajuk dipengaruhi oleh sifat logam, artinya setiap logam mempunyai pergerakan berbeda dari akar ke tajuk. Alloway dalam Hayati (2010) mengklasifikasikan unsur $\mathrm{Mn}, \mathrm{Zn}, \mathrm{Cd}, \mathrm{B}$, dan Se sebagai unsur yang cepat pindah atau bergerak ke tajuk tanaman; Ni, Co dan $\mathrm{Cu}$ tergolong intermediate, $\mathrm{Cr}, \mathrm{Pb}$ dan $\mathrm{Hg}$ tergolong logam yang paling lambat bergerak ke tajuk. Klasifikasi tersebut memperkuat penelitian ini dimana nilai TF tanaman bayam dalam menyerap logam $\mathrm{Pb}$ dibawah 1. Selain sifat logam, sifat tanaman turut menentukan pergerakan logam dari akar ke tajuk. Tanaman secara aktif memiliki mekanisme tersendiri untuk mencegah pergerakan unsur dari akar ke tajuk dengan cara mensekuestrasi logam di bagian akar, khususnya di bagian vakuola atau dinding sel (Gupta dan Sinha, 2008). Pernyataan yang sama juga diungkapkan oleh Yoon et al., (2006) yang menyatakan terkadang akar juga mempunyai sistem penghentian transpor logam menuju daun terutama logam non esensial, sehingga ada penumpukkan logam di akar. Logam $\mathrm{Pb}$ sebagai salah satu logam non esensial bagi tanaman memiliki kecendrungan ditumpuk oleh akar daripada ditransfer ke bagian tajuk. 


\section{e. Kinetika Reaksi Penyerapan Logam Pb Pada Tanaman bayam cabut (Amaranthus tricolor L.)}

Kinetika reaksi adalah cabang ilmu kimia yang mengkaji kecepatan atau laju terjadinya suatu reaksi kimia. Di dalam proses penyerapan logam $\mathrm{Pb}$ pada tanaman bayam cabut (Amaranthus tricolor L.) ini juga terjadi reaksi kimia yang memungkinkan dihitungnya besar kecepatan atau laju dari proses tersebut. Kinetika reaksi orde 1 dapat dihitung dangan memplot nilai In $[\mathrm{Pb}]$ dan hari pengukuran (t) ke dalam grafik. Kinetika reaksi orde 2 dapat dihitung dangan memplot nilai $\frac{1}{[P b]}$ dan hari pengukuran (t) ke dalam grafik. Grafik kinetika reaksi orde 1 dan 2 pada penelitian ditunjukan pada Gambar 1 berikut :

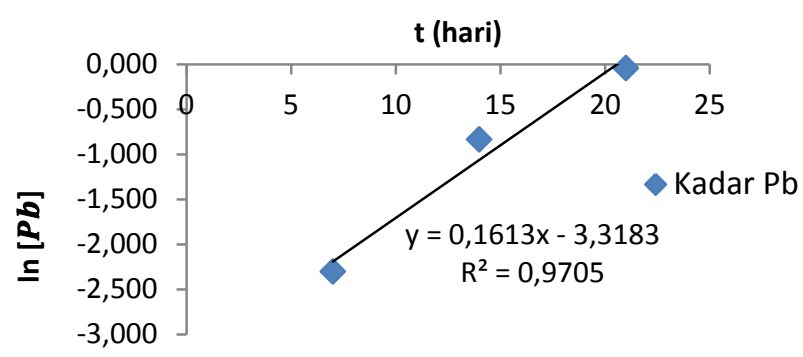

a. Grafik $\ln [P b]$ vs t (hari)

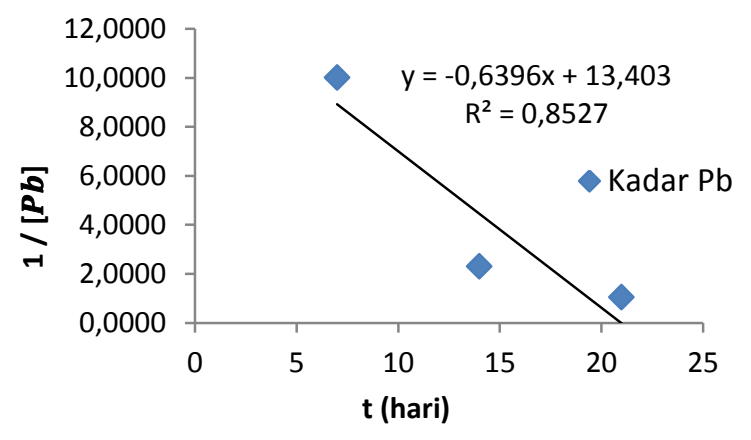

b. Grafik $1 /[P b]$ vs t (hari)

Gambar 1. Grafik kinetika reaksi orde 1 (a) dan orde 2 (b)

Berdasarkan Gambar 1 dapat disimpulkan bahwa orde reaksi yang terjadi pada proses penyerapan logam $\mathrm{Pb}$ pada tanaman bayam cabut (Amaranthus tricolor L.) mengikuti kinetika orde 1. Hal ini dapat dilihat dari kelinieritasan kurva yang ditunjukan oleh koefisien korelasi linier. Nilai koefisien korelasi linier pada kurva orde $1(0,9705)$ lebih besar dibandingkan dengan kurva orde 2 $(0,8527)$. Hasil ini juga sesuai dengan pernyataan Mangkoedihardjo dan Samudro (2010) yang menyatakan bahwa waktu remediasi dapat dihitung dengan menetapkan kinetika zat orde 1. Kinetika reaksi yang mengikuti orde 1 menunjukan bahwa laju dari reaksi ini bergantung pada konsetrasi reaktan dipangkatkan dengan satu atau laju reaksi berbanding lurus dengan konsentrasi pereaksi.

Nilai konstanta laju reaksi penyerapan dapat dilihat berdasarkan kemiringan (slope) pada persamaan garis lurus yang terbentuk pada orde 1, yaitu sebesar 0,1613 hari $^{-1}$. Nilai konstanta laju reaksi yang diperoleh pada penelitian ini merupakan nilai konstanta laju reaksi pada tajuk tanaman. Nilai konstanta laju reaksi (k) ini dapat digunakan untuk menghitung tingkat pencemaran pada waktu tertentu maupun untuk menentukan waktu yang diperlukan untuk menurunkan pencemar pada tingkat tertentu.

\section{c. Kesimpulan}

Kesimpulan dari penelitian ini adalah :

1. Nilai bioconcentration factor (BCF) yang diperoleh pada penelitian ini adalah sebesar 0,071 . Nilai tersebut berada pada rentang 0,01-0,1 yang menujukan tanaman bayam cabut (Amaranthus tricolor $\mathrm{L}$.) termasuk akumulator rendah dalam meremediasi logam timbal ( $\mathrm{Pb}$ ) yang mencemari tanah yang memiliki pH dengan rentang 6,2-6,9. Walaupun penyerapannya tergolong rendah, tetapi kondisi tanaman yang secara visual masih sehat dan baik serta pertumbuhannya yang cepat menjadikan tanaman ini masih dapat dipertimbangkan sebagai agen fitoremediasi pencemaran $\mathrm{Pb}$ di tanah. Namun tanaman yang telah digunakan harus diolah lebih lanjut dan tidak disarankan untuk dikonsumsi karena telah melebihi baku mutu yang diizikan di dalam tanaman pangan.

2. Nilai translocation factor (TF) yang diperoleh pada penelitian ini adalah sebesar 0,12 . Nilai tersebut lebih kecil daripada $1(<1)$ sehingga mekasnisme atau proses yang terjadi pada penyerapan logam $\mathrm{Pb}$ pada tanaman bayam cabut (Amaranthus tricolor L.) adalah fitostabilisasi. 
3. Nilai konstanta laju reaksi $(k)$ penyerapan logam timbal $(\mathrm{Pb})$ pada tanaman bayam cabut (Amaranthus tricolor L.) adalah 0,1613 hari $^{-1}$ dan mengikuti orde 1. Hal ini menunjukan bahwa laju dari reaksi ini bergantung pada konsetrasi reaktan dipangkatkan dengan satu atau laju reaksi berbanding lurus dengan konsentrasi pereaksi.

\section{d. Ucapan Terima Kasih}

Terima kasih penulis ucapkan kepada seluruh pihak yang telah membantu dalam penyelesaian penelitian ini. Kepada ibu Ir. Rita Hayati, M. Si dan ibu Titin Anita Zahara, S.Si, M.Si selaku dosen pembimbing serta kepada ibu Berlian Sitorus, S.Si, M.Si, M.Sc dan ibu Isna Apriani, S.T, M.Si selaku dosen penguji yang telah memberikan masukan dan koreksi yang sangat bermanfaat dalam penyelesaian penelitian ini.

\section{e. Referensi}

Adelia. 2004. Evaluasi Kadar Ambien Logam Berat Nikel (Ni) Dan Timbal (Pb) Dalam Tanah Sebagai Dasar Penyempurnaan Kriteria Baku Mutu Tanah Di Indonesia. Skripsi. Institut Pertanian Bogor. Bogor.

Charlena. 2004. Pencemaran Logam Berat Timbal (Pb) dan Cadmium (Cd) pada Sayur-Sayuran. http://www.rudyct.com/PPS702 ipb/09145/charlena.pdf. Diakses tanggal 29 November 2011.

Fitter A.H. dan Hay,R.K.M. 1991. Fisiologi Lingkungan Tanaman. Universitas Gajah Mada. Yokyakarta.

Gupta, A. K and Sinha, S. 2008. Decontamination and/or revegetation of fly ash dykes through naturally growing plants, Journal of Hazardous Materials 153, Page 1078-1084.

Haque, N., J.R. Peralta-Videa, G.L. Jones, T.E. Gill, and J.L. Gardea-Torresdey. 2008. Screening the phytoremediation potential of desert broom (Baccharis sarothroides Gray) growing on mine tailings in Arizona, USA. Environmental Pollution 153:362-368.

Hayati, Rita. 2010. Karakterisasi Abu Terbang (Fly Ash) Dan Eksplorasi Vegetasi Fitoremediator di Area Landfill Abu Terbang Untuk Pengelolaan Ramah Lingkungan. Sekolah Pasca Sarjana. Institut Pertanian Bogor. Bogor.

Juhaeti T, Sharif F, Hidayati N. 2004. Inventarisasi Tumbuhan Potensial Untuk Fitoremediasi. Jurnal Biodiversitas. Vol. 6 N0. 1 hal 31-33.

Lakitan B. 2001. Dasar -dasar Fisiologi Tumbuhan. Raja Grafindo Persada. Jakarta.

Liong, S., Noor, A., Tana, P., Abdullah, A. 2010. Studi Fitoakumulasi Pb dalam Kangkung Darat (Ipomoae reptans Poir). Jurusan Kimia Fakultas MIPA Universitas Hasanuddin. Makasar.

Malayeri, B.E., A. Chehregani, N. Yousefi, and B. Lorestani. 2008. Identification of the hyperaccumulator plants in copper and iron mine in Iran. Pakistan Journal of Biological Sciences 11: 490-492.

Mangkoedihardjo, S dan Samudro, G. 2010. Fitoteknologi Terapan. Graha Ilmu. Yogyakarta.

Ministry of State for Population and Enviromental of Indonesia, and Dalhousie, University Canada. 1992. Environmental Management in Indonesia. Report of Soil Quality Standars for Indonesia.

Pivetz, B.E. 2001. Phytoremediation of Contaminated Soil and Ground Water at Hazardous Waste Sites. EPA (United States Environmental Protection Agency), Office of Research and Development. pp. $1-36$.

Riwandi. 2001. Kajian Stabilitas Gambut Tropika Indonesia Berdasarkan Analisis Kehilangan Karbon Organik, Sifat Fisiko Kimia dan Komposisi Bahan Gambut. Tesis. Program Pascasarjana. Institut Pertanian Bogor. Bogor.

Rumanjar, Antonius Theodorus, B. 2010. Penjajakan Kadar Logam Berat Pb Pada Tanaman Kangkung Darat (Ipomea Reptans Poir) Asal Kecamatan Medan Deli dan Kangkung Air (Ipomea Aquatica Forsk) Asal Kecamatan Sunggal Kota Medan. Departemen Ilmu Tanah Fakultas Pertanian. Universitas Sumatera Utara. Medan.

SNI 7387 : 2009 tentang Batasan Maksimum Cemaran Logam Berat Dalam Pangan

Yoon, J., C. Xinde, Z. Qixing, and L.Q. Ma. 2006. Accumulation of Pb, $\mathrm{Cu}$, and $\mathrm{Zn}$ in Native Plants Growing on a Contaminated Florida Site. Science of the Total Environment: 456-464. 